\title{
A SIMULATION OF THE SAN ANDREAS FAULT EXPERIMENT
}

\section{RUSSELL W. AGREEN \\ DAVID E. SMITH}
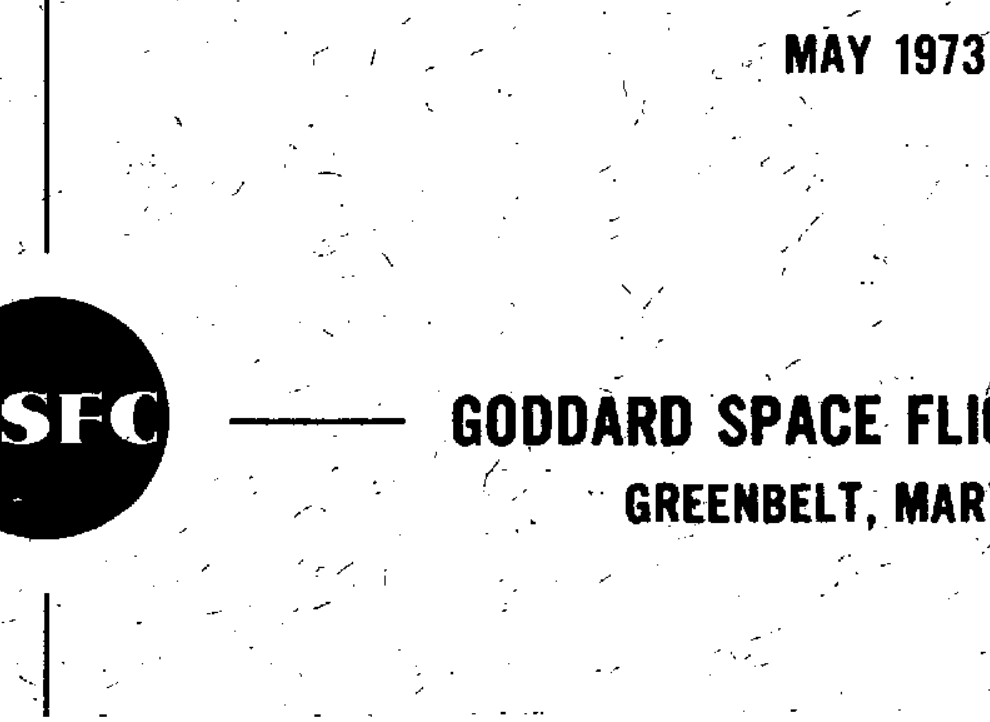

(NASA-TM-X-70439) A SIMULATION OF TEE

SAM ANDREAS FAULT EXPEEIMENT (NASA)

$43 \mathrm{p} \mathrm{HC} \$ 4.25$

CSCL $08 \mathrm{~B}$

N73-30338 
A SIMULATION OF THE SAN ANDREAS FAULT EXPERIMENT

Russell W. Agreen

David E. Smith

May 1973

GODDARD SPACE FLIGHT CENTER

Greenbelt, Maryland 


\title{
A SIMULATION OF THE SAN ANDREAS FAULT EXPERIMENT
}

\author{
Russell W. Agreen \\ David E. Smith
}

\begin{abstract}
The San Andreas Fault Experiment (SAFE), which employs two laser tracking systems for measuring the relative motion of two points on opposite sides of the fault, has been simulated for an eight year observation period. The two tracking stations are located near San Diego on the western side of the fault and near Quincy on the eastern side; they are roughly 900 kilometers apart. Both will simultaneously track laser reflector equipped satellites as they pass near the stations.
\end{abstract}

Tracking of the Beacon Explorer C Spacecraft has been simulated for these two stations during August and September for eight consecutive years. An error analysis of the recovery of the relative location of Quincy from the data has been made, allowing for model errors in the mass of the earth, the gravity field, solar radiation pressure, atmospheric drag, errors in the position of the San Diego site, and laser systems range biases and noise. The results of this simulation indicate that the distance of Quincy from San Diego will be determined each year with a precision of about 10 centimeters. This figure is based on the accuracy of earth models and other parameters available in 1972. Projected improvements in these model parameters and in the laser systems over the next few years will bring the precision to the $3 \mathrm{~cm}$ level in 1976 and to about 1 to $2 \mathrm{~cm}$ by 1980 . 


\section{CONTENTS}

$\underline{\text { Page }}$

ABSTRACT . . . . . . . . . . . . . . . . •

INTRODUCTION . . . . . . . . . . . . . . . .

STRUCTURE

ERROR SOURCES

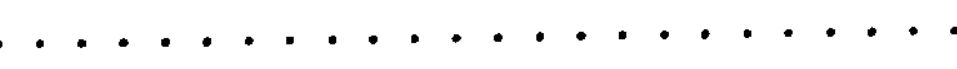

ANALYSIS . . . . . . . . . . . . . . . . . . • •

ACKNOWLEDGMENT . . . . . . . . . . . . . . . . •

REFERENCES . . . . . . . . . . . . . . . . . . .

TABLES

Table

1 Periods for Which Simulated Data Were Prepared . . . . .

2 Error Sources . . . . . . . . . . . . .

3 Expected Errors in QUINCY Location for 2-pass Solution . . .

4 Expected Errors in QUINCY Location for 3-pass Solution . . .

$5 \quad$ Expected Errors in QUINCY Location for 4-pass Solution . . •

6 Expected Errors in QUnNCY Location for 5-pass Solution... .

$7 \quad$ Expected Errors in QUTNCY Location for Middle-3-pass Solution . . . . . . . . . . . .

8 Components of the Baseline Precision . . . . . . . 


\section{TABLES (Continued)}

$\underline{\text { Table }}$

$\underline{\text { Page }}$

$9 \quad$ Expected Improvements in the Major Error Sources . . . . 34

10 Projected Ability to Recover Safe Baseline (Centimeters) . . . 35

\section{ILLUSTRATIONS}

Figure

$\underline{\text { Page }}$

1 The San Andreas Fault Experiment, 1972 . . . . . . 36

2 Groundtracks of 5 Consecutive Passes of the BE-C Satellite During the San Andreas Fault Experiment (SAFE) . . . . 37

3 Geocentric Coordinates of Tracking Stations . . . . . . 38 


\section{A SIMULATION OF THE SAN ANDREAS FAULT EXPERIMENT}

\section{INTRODUCTION}

The San Andreas fault system in California and Mexico is the boundary between the North American plate to the east and the Pacific plate to the west. It is estimated that the Pacific plate, which includes southwestern California, is moving past the North American plate at an average rate of four to seven centimeters per year. A more accurate determination of the relative motion of these two large plates would assist efforts of earthquake prediction in California and, perhaps, eventual control since it would yield information as to the magnitude of integrated strain buildup across all the faults in the region. Such a method for determining the relative motion of two plates would find use in many areas of the world and perhaps make possible a global picture of plate motions and strain buildup at some future time.

At Goddard Space Flight Center, an experiment has been proposed which has as its objective the recovery of this relative motion between the North American and Pacific plates to an accuracy of better than one centimeter per year. The principle of the experiment is to precisely determine the distance between two points established on opposite sides of the fault and sufficiently distant from the fault so as to be uneffected by local movements and to repeat the experiment every year for several years. The technique that will be employed is trilateration using laser tracking of satellites. The laser tracking sites that have 
been selected are near Quincy, California on the North American plate and near San Diego on the Pacific plate (Figure 1). Based on the assumption that these sites are not significantly corrupted by local effects, a geometric conversion from relative site velocity to relative plate velocity can be made.

The relative motion of one laser site with respect to the other will be determined after several years of measurements by fitting a linear least squares solution to the observed intersite distances. The position of one station with respect to the other will be recovered each year through dynamic orbital solutions based upon data obtained in approximately two months of simultaneous laser tracking of geodetic satellites equipped with laser retro-reflectors. The primary satellite for the experiment will be the Beacon Explorer $\mathrm{C}$ in a near circular orbit at an altitude of about $1000 \mathrm{~km}$ with an inclination to the equator of 41 degrees 。

This document presents the results of a simulation of the San Andreas Fault Experiment (SAFE) for an eight year period. The effect of errors in the orbit force models, in the coordinates of the laser stations, and in the laser systems on the determination of the relative location of the two stations have been computed. All results are based upon 16 days of successful simultaneous data acquisition of the Beacon-C satellite over a 2 month period each year.

There are, of course, alternative approaches to that described here for determining the motion between points on the order of $1000 \mathrm{~km}$ apart. Surface measurements, obtained by geodometer, could be used, but it is not clear if 
they could obtain the precision anticipated by the technique to be described here. Alternatively, geometric satellite approaches of the kind investigated by Vonbon, Escobal et al., and others could be employed. In particular, Escobal et al. at JPL recommend a technique called $3 \mathrm{D}-$ Multilateration in which a number of laser tracking stations simultaneously track a satellite as it crosses the sky. From a relatively few range measurements from each site, it is possible to derive the locations of the laser stations and, if required, the position of the satellite from purely geometric considerations. The power of this technique lies in its non-involvement in orbital dynamics and the forces that determine the satellite's motion. The accuracy with which the locations of the stations can be derived with this approach is comparable to the accuracies of the lasers; thus, a network of one centimeter lasers could produce coordinates accurate to one or two centimeters in each coordinate.

In contrast, the technique that is simulated here is a dynamical geodesy approach that is based on a detailed knowledge of the forces acting on the satellite. Further, the concept is designed to give high precision (measurement repeatability) rather than accuracy because of a basic uncertainty in scale arising from uncertainties in fundamental parameters, such as the mass of the earth. The dynamic technique has the advantage of being applicable to just 2 stations, in contrast to the minimum of 6 for the geometric approach, and to be workable with 5 to $10 \mathrm{~cm}$ laser systems because of the larger amounts of data involved. 


\section{STRUCTURE}

The simulation was accomplished with the use of an error analysis computer program designed to compute the effects of random and systematic errors on minimum variance orbit determination (Martin).

Each year of the simulated experiment was composed of sixteen orbital arcs of Beacon Explorer $\mathrm{C}(\mathrm{BE}-\mathrm{C})$ laser range data acquired simultaneously at both the Quincy and San Diego sites. The BE-C satellite was selected for the experiment because it has been used successfully in previous tracking experiments, and it has a favorable inclination for the current project. The groundiracks of this satellite (Figure 2) indicate that each day there are five consecutive passes which are above 10 degrees elevation from both laser sites. On occasions there is a sixth pass which reaches 10 degrees elevation, but in this simulation the possibility of obtaining tracking data on this pass has been ignored. A basic set of five passes has been selected from each tracking day. Five different solutions have been simulated for each of the 8 years. in the first of these, each orbital are (one day's observations) consists of the basic five consecutive passes. In the other four solutions, an orbital arc consisted of subsets of these five passes. The subsets selected were the earliest two passes (out of five), the earliest three passes, the earliest four, and the middle three passes. Consequently, in any given solution, each orbital arc had almost the same geometry with respect to the stations on each of the 16 days of tracking data selected from the two months observation period. 
The pattern of groundtracks for BE-C repeats itself in slightly less than one day, and on each successive day it moves slightly eastward. This eastward drift is such that it requires about five to six days before the second pass is in the original position of the first pass. Figure 2 shows the groundtracks of the BE-C satellite and their eastward drift. The pass labeled number 1 is the approximate western-most position of the first of the five consecutive passes while the unnumbered pass represents its eastern-most position, which occurs about six days later. The sixteen days of simultaneous simulated data were "acquired" during two periods of 8 days, approximately one month apart, in August and September of each year as shown in Table 1. By using simulated data on consecutive days, the variable geometry, as shown in Figure 2, would be inherent in the data. Taking two periods separated by about a month was an attempt to include in the simulation longer term effects, such as motion of perigee, which would naturally be included in an actual two month observing program. However, it is not clear that such effects are an important factor in the outcome of the experiment.

It is of interest to note that the earliest three passes of the day are largely perpendicular to the baseline while the latter two passes become more parallel. It is a well known fact that the largest component of error in orbit determination is usually in the direction of motion of the satellite (along track) rather than normal to the velocity vector (cross-track or radial direction). Thus, it might be expected that this along track error would be more detrimental to baseline recoveries involving the latter passes of the day as opposed to those tending 
toward use of the earlier passes. This line of thought was used in the selection of the subsets of simulated data used in the five separate solutions to the experiment, and the concept has been shown to be largely correct.

For this simulation, the San Diego laser was positioned at $32^{\circ} 30^{\prime}$ north latitude and $243^{\circ}$ east longitude while the Quincy laser was at $40^{\circ}$ north latitude and $239^{\circ}$ east longitude. The actual locations of the lasers to be used in the experiment are San Diego (Otay Mountain), $32^{\circ} 36^{\prime}$ north, $243^{\circ} 10^{\prime}$ east, and Quincy, $39^{\circ} 58^{\prime}$ north, $239^{\circ} 03^{\prime}$ east. Both stations were placed on the spheroid, i。e zero meters in height. Each site began acquiring data on any given pass as soon as the elevation of BE-C from the laser mount exceeded ten degrees and ceased acquisition when the elevation again receded below ten degrees. One range was simulated every ten seconds while the lasers were tracking. As a consequence, each pass of data consisted of mostly simultaneous observations with some single site daca at the beginning and end. Only range data were simulated although azimuth and elevation data of fair quality will be collected in actual practice. However, at present it is not planned to use the angle measurements because of possible biases.

Each of the five separate solutions have been simulated in each of eight years, 1970 through 1977, yielding eight independent solutions for the location of the Quincy laser. The accuracies of the recovered parameters are limited by the errors in the orbital dynamics. However, an examination of the varying effect 
that these error sources have on the solutions over the eight years has enabled the precision of the recovered coordinates and baseline to be determined for each of the five solutions.

\section{ERROR SOURCES}

The determination of the location of Quincy with respect to the San Diego station in the actual experiment will be accomplished using standard procedures in dynamical geodesy. One site's position will be regarded as fixed and known while the other's coordinates will be regarded as recoverable parameters, along with the satellite position and velocity. In this simulation, the location of Quincy and the satellite orbit will be recovered simultaneously from each orbital arc of $2,3,4$ or 5 passes. Thus, in principle, during one year's experiment involving sixteen days of tracking, a total of sixteen sets of orbit parameters will be obtained and sixteen determinations of the Quincy location. In practice, all sixteen data sets will be handled simultaneously in a multiple-arc least squares analysis in which sixteen sets of orbit parameters are recovered but only one value for the Quincy location is recovered. This approach, in effect, provides a dynamic averaging of the results for Quincy from the sixteen single days of tracking.

In this "multi-arc" mode, there are inner iterations and outer iterations. In the former, the data in each orbital arc are used to determine the satellite's position and velocity at an epoch. After all inner iterations are completed, an outer iteration is undertaken in which the data are used to determine the unknown 
parameters common to all the arcs, in this case the location of Quincy. This scheme is repeated until certain convergence criteria are satisfied. This is the procedure that will be used in the actual experiment and has also been used in the simulation.

The problem with this method of analysis lies in the errors inherent in the satellite force model and in the position of the San Diego station used in the calculations. These errors, together with those of the laser systems, are the limiting factors in determining the location of Quincy, and it is essentially with the propagation of these errors into the Quincy coordinates that this paper is primarily concerned. Table 2 lists the principle sources of error and their magnitudes. Each of these sources has been included in the analysis, and the propagation of these errors on the recovered coordinates has been computed for each of the five solutions in each year。 The magnitudes of the errors listed in Table 2 are believed to be commensurate with our knowledge in 1972. The error in the value of the gravitational constant was taken as one part per million and reflects the quality of recent determinations (Esposito and Wong)。 Errors in the geopotential were modeled by one-fourth of the differences between the coefficients of the Smithsonian Astrophysical Observatory (SAO) MI gravity field (Lundquist and Veis) and APL 3.5 (Guier and Newton) gravity field through degree and order eight. This model has been found by Martin and Roy (Martin and Roy) to be a suitable error model for the SAO 1969. Standard Earth II. The geocentric position 
of the San Diego site was assumed to be in error by 5 meters in each coordinate. Nominal errors in the geopotential coefficients $C(19,13)$ and $S(19,13)$ were also included because the BE-C orbit is resonant with these terms. Errors in the models for radiation pressure and atmospheric drag were included at the $10 \%$ level. Both laser systems were modeled as having a ten centimeter bias and 20 centimeter noise at a pulse rate of 1 per ten seconds.

\section{ANALYSIS}

As previously mentioned, each multiple arc solution yields an adjustment of the Quincy laser site's longitude, latitude, and height. Tables 3 through 7 show the error contributions to these parameters and to the San Diego-Quincy baseline arising from the effects of GM, gravity, system biases, radiation pressure, air drag, and errors in the location of the San Diego station. The baseline errors have been computed from the errors in the other parameters as follows. Let the locations of the two tracking stations be $\left(r_{1}, \phi_{1}, \lambda_{1}\right)$, and $\left(r_{2}, \phi_{2}, \lambda_{2}\right)$, where $\mathbf{r}$ is the radial distance from the center of the earth and $\phi$ and $\lambda$ are the geocentric latitude and longitude. Let $D$ be the chord length between the two stations. Then we have, from Figure 3, for small departures from a sphere;

$$
\mathrm{D}^{2}=\mathrm{r}_{1}{ }^{2}+\mathrm{r}_{2}^{2}-2 \mathrm{r}_{1} \mathrm{r}_{2} \cos \theta
$$


where $\theta$ is the geocentric angle between the stations, and

$$
\cos \theta=\sin \phi_{1} \sin \phi_{2}+\cos \phi_{1} \cos \phi_{2} \cos \left(\lambda_{1}-\lambda_{2}\right)
$$

Differentiating the above equations leads to the following expression for the change in baseline (chord length) arising from changes in $r, \phi$, and $\lambda$ at each site:

$$
\begin{aligned}
& \delta \mathrm{D}=\frac{1}{\mathrm{D}}\left(\mathrm{r}_{1}-\mathrm{r}_{2} \cos \theta\right) \delta \mathrm{r}_{1}+\frac{1}{\mathrm{D}}\left(\mathrm{r}_{2}-\mathrm{r}_{1} \cos \theta\right) \delta \mathrm{r}_{2} \\
& +\frac{\mathrm{r}_{1} \mathrm{r}_{2}}{\mathrm{D}}\left[\sin \phi_{1} \cos \phi_{2} \cos \left(\lambda_{2}-\lambda_{1}\right)-\cos \phi_{1} \sin \phi_{2}\right] \delta \phi_{1} \\
& +\frac{\mathrm{r}_{1} \mathrm{r}_{2}}{\mathrm{D}}\left[\cos \phi_{1} \sin \phi_{2} \cos \left(\lambda_{2}-\lambda_{1}\right)-\sin \phi_{1} \cos \phi_{2}\right] \delta \phi_{2} \\
& +\frac{\mathrm{r}_{1} \mathrm{r}_{2}}{\mathrm{D}} \cos \phi_{1} \cos \phi_{2} \sin \left(\lambda_{2}-\lambda_{1}\right)\left(\delta \lambda_{1}-\delta \lambda_{2}\right)
\end{aligned}
$$

$\delta \mathrm{D}, \delta \mathbf{r}, \delta \phi$, and $\delta \lambda$ are the errors in the baseline and the coordinates of the two sites. Without any loss of accuracy, the error in radial distance, $\delta \mathrm{r}$, may be replaced with $\delta \mathrm{h}$, the error in height. The above equation can be simplified by putting $\delta \mathrm{r}_{2}, \delta \phi_{2}, \delta \lambda_{2}$ (errors in San Diego position) equal to zero when only the effects of dynamic errors, such as the gravity field, are being computed.

Tabie 3 gives the errors for the solution based on the first two observable passes each day (2-pass solution); Table 4 gives the errors for the solution from the first three observable passes (3-pass solution), Table 5 for the 4-pass solution, Table 6 for the 5-pass solution, and Table 7 gives the errors for the solution obtained from the middle three observable passes (middle 3-pass solution). 
In the interpretation of these tables, it is important to remember that they are based on knowledge and capabilities in 1972.

From Tables 3 through 7, it is immediately evident that errors in solar radiation pressure, air drag, and the resonance terms are comparatively negligible. None of these sources contributes more than a centimeter or two to the total. Further, the effect of an error in GM on the longitude is reasonably constant from year to year for all the solutions, with standards deviations about the means of 2 to 12 centimeters. For the latitude and height, the variability of the GM error is somewhat larger. The size of the height error due to GM is maximally 5 meters, and this indicates the limitations on the accuracy of the height that can be presently determined. However, the variability of the GM error (on the height) between the solutions is only about 5 to $10 \%$ of the magnitude, so the contribution of GM error to the precision is only 2 or 3 tens of centimeters at most and generally less than 10 centimeters. Inspection of Tables 3 through 7 shows the best Quincy coordinate solutions, considering GM errors alone, are the 3 and 5 pass solutions.

A similar situation exists for the gravity model error; that is, there is considerable variation between the solutions as to the effect of gravity errors. In general, the magnitude is similar to the GM error, but gravity errors have a greater percentage variation so that the contribution to the precision is more comparable to the contribution to the accuracy. This makes gravity error the 
largest single error source and properly modeling the gravity field the major problem of the experiment. It is interesting to note that the 3 pass and 5 pass solutions are clearly the best configurations for determining the longitude with figures of 4 and 5 centimeters(precision) respectively, although none of the solutions are very bad. For the latitude, the 3 pass solution $(7 \mathrm{~cm})$ is also best followed by the $2-$ and 5 -pass solutions at around 12 and 14 $\mathrm{cm}$, respectively. For the height, the 2- and 5-pass solutions are equally good at about 14 or $15 \mathrm{~cm}$ while all other solutions are approximately twice as bad. It is interesting to note, having only considered GM and gravity errors, that certain solutions are better for one parameter than for another. For example, the best solution for the height is the 5 -pass configuration, while the best solution for the latitude (so far) is the 3-pass solution. Thus, to obtain the "best" coordinates in an actual experiment may require obtaining the different components of the Quincy location from different solutions derived from subsets of the same data

In the previous section, it was briefly mentioned that geometry played an important part in the solutions, and this is demonstrated in a comparison of the GM and gravity errors in the 3-pass and middle 3-pass solutions. The only difference between the data sets used in these solutions is that pass one of the 3-pass data set has been omitted and pass 4 included in the middle 3-pass data set. Passes 2 and 3 are common to both data sets. A comparison of the error propagation in these solutions (Tables 4 and 7 ) shows that the GM effect is about 
twice as large for the middle 3-pass solution in all three components. Further, the gravity error is about 3 times larger for the same solution for longitude and latitude while comparable for the height. Thus the middle 3-pass solution is clearly worse than the 3-pass solution. Our tentative interpretation of this result is that since the San Diego station is about 4 degrees east of Quincy, pass 1 is more perpendicular to the San Diego-Quincy baseline than pass 4 , and therefore, the along track orbital errors propagate more strongly in pass 4 than pass 1. Since the along track errors are normally about an order of magnitude larger than those perpendicular to the direction of motion, pass 4 is inferior to pass 1 , and thus, the 3 pass solution is better than the middle 3 pass solution. This explanation cannot, however, be completely correct because it would suggest that the latitude in the 3-pass solution should be worse than in the middle 3-pass solution-and this is not the case. Nevertheless, we do feel that the differences between these two solutions reflect the geometrical differences contained within the data sets.

The effects of $10 \mathrm{~cm}$ range biases on a particular parameter show remarkable constancy from year to year within a given solution. However, they show surprising variation from one solution to the next. In the simulation, $10 \mathrm{~cm}$ has been added to each range measurement to represent a $10 \mathrm{~cm}$ bias for the entire experiment, and this is probably unrealistic. Over a long period of time, it is probable that the bias will appear more like noise than a bias. Thus, the simulations probably indicate the true magnitude of a bias on the solution but may be 
thought to over-estimate the stability of the bias, and its effect, from year to year. There is evidence that supports this hypothesis from an experiment conducted at GSFC in 1971 (Dunn et al.). Two laser tracking systems stationed within 25 meters of each other tracked the BE-C satellite simultaneously on about 20 occasions during a 6-week period. A comparison of the measurements showed range differences (biases) between the systems on a pass-by-pass basis of up to $50 \mathrm{~cm}$, which was comparable to the noise level of the measurements. Over all 20 passes the average bias was $2 \mathrm{~cm}$. Thus, the biases do tend to vary and during one year of the experiment will probably average out to near zero. The actual experiment will be conducted with 5 to $10 \mathrm{~cm}$ noise level systems, implying similar sized pass to pass biases. But over two months, the average bias will probably be of the order of a centimeter or less. Therefore, the simulation, which is based on $10 \mathrm{~cm}$ constant bias, is more likely to be pessimistic than optimistic.

Certain general conclusions about the effect of system biases can be drawn from Tables 3 to 7 . Assuming $10 \mathrm{~cm}$ biases at each station, it is apparent that (1) they only affect the longitude (of Quincy) by a few centimeters (true for all solutions), (2) the San Diego bias introduces larger errors in the latitude (of Quincy) when fewer passes are used in the solution, $\dot{i}_{0} e_{\circ}$, the 5 -pass solution is considerably better than the 2-pass solution, (3) the Quincy bias has the larger effect on the height (of Quincy) and is largely the same in all solutions, and (4) the effects of biases are very stable from year to year for all solutions and do not appear to be a problem at the 5 to $10 \mathrm{~cm}$ level. 
Tables 3 to 7 show that air drag and radiation pressure yield insignificant contributions to the errors. A $10 \%$ scale error has been used as the model for these errors, and although this is probably not very realistic, it indicates the general order of magnitude of the error propagation. Since a $10 \%$ constant error contributes only one or two centimeters (at most) error to the longitude, latitude, and height, it is unlikely that a time varying error of up to $20 \%$, which is perhaps more realistic, will have any larger effect. Any scale error in the drag or radiation pressure models can be removed by adjusting the coefficient of drag or the solar constant within these models. This forces the model errors to vary about an average of zero.

Generally, the higher the degree and order of a term in the expansion of the gravity field, the smaller its effect on the orbit. This situation, however, breaks down when the orbit approaches a resonance with the rotation of the earth. For the BE-C satellite, these terms are of order 13, and consequently, the effect of a typical 13th order resonant term has been included in this analysis. The resonant period for this satellite with these terms is about 5.6 days, and they can cause periodic perturbations of the order of 10 meters amplitude perpendicular to the velocity vector with much larger effects along the track of the satellite. Probably because the orbital arcs in this experiment will only be about 6 hours, which is short compared to the resonance period, these terms appear to be negligible in their contribution to the errors, as evidenced by Tables 3 to 7 . 
The effect of errors in the location of the fixed station, San Diego, are shown in the last three columns of Tables 3 to 7. Longitude errors at San Diego have no effect on the determination of Quincy except to introduce a rotation about the earth's rotation axis. The large longitude error of 454 centimeters at Quincy in all the solutions is the error at San Diego (5 meters) times the ratio of the cosines of the latitudes of the two stations. Since a longitude error at San Diego is equivalent only to a rotation, there is no propagation of San Diego longitude into the Quincy latitude, height or the baseline. A 5 meter error in the San Diego latitude effects the Quincy longitude and height by 2 or 3 tens of centimeters and the Quincy latitude by about 5 meters. The latitude effect is essentially an adjustment of Quincy in the same direction as the error in San Diego and with about the same magnitude; the effect on the baseline is a few tens of centimeters with a stability of 2 to $4 \mathrm{~cm}$. Table 6 suggests that the 5-pass solution is the best in this respect.

A height error at San Diego has greater variability in its effect among solutions than either the latitude or longitude errors. In the case of the 2-pass solution, the height error has propagated strongly into the latitude (and of course the baseline), while in the 3-pass solution, it has been divided between the latitude and height. In the 4- and 5-pass solutions, the error has propagated mostly into the height. Thus, as the number of passes in the orbital arc increases, the height error at San Diego propagates more directly into the height at Quincy and amounts to over 4 meters in the 5-pass solution (Tables 5 and 6 ). The effect of 
height on the baseline tends to get smaller as the number of passes per solution increases. In the middle-3-pass solution, the effect of a height error at San Diego on Quincy is comparable to the other solutions with the principal effect being in the height. The baseline stability of the middle-3-pass solutions is not, however, as good as the other solutions, particularly the 3 - and 5-pass solutions which have an rms about the average of roughly $4 \mathrm{~cm}$.

For the purpose of detecting the relative motion of the two laser stations, accuracy is not as important as precision. In other words, it is necessary to know how well the recovery of the baseline can be repeated with different sets of data rather than the absolute accuracy of any particular recovery. Table 8 shows the components of the precision in the determination of the baseline for all five solutions. The numbers in this table have already been given in Tables 3 to 7 as the rms's of the baselines, but are reproduced in Table 8 for convenience in the ensuing discussion. Although the purpose of the experiment is to measure the three dimensional relative motion of the two stations, the change in the baseline is probably the single most important parameter and of the most immediate application. Thus the following discussion is mainly concerned with the baseline and its recovery.

In Table 8 it is clearly apparent that the major sources of error are the gravitational field, GM, and the latitude and height of the San Diego station. Further, the best solutions are the 3-pass and 5-pass solutions, as evidenced 
by the last column (RSS) which is the root sum of the squares of the values in the other columns. It is interesting to note how much more sensitive the 4-pass solution is to errors in GM than the 5-pass solution. Indeed, the latter is almost insensitive to $\mathrm{GM}_{\text {, }}$ and if the gravity error is ignored, it is on a par with the 3-pass solution. It is not evident why the 4-pass solution should be considerably less effective than the 3 or 5 pass solution, but it is probably related to the differences in geometry. The use of only 2 passes appears not to provide enough data and/or geometry for an adequate solution. The middle 3-pass solution was not expected to do nearly as well as the 3-pass solution because of the replacement of the first pass, which is essentially perpendicular to the baseline, with the fourth pass, which is essentially parallel to the baseline, as discussed earlier. It should also be noted that the computation of the root sum squares is almost completely dependent upon the error contributions of the aforementioned four major error sources. As an example, if we consider only these four error sources, the root sum square for the early three passes solution becomes 8.9 instead of 9.2 centimeters.

In summary, Table 8 indicates that we can anticipate a precision of about $10 \mathrm{~cm}$ in the baseline during 1972-73 experiments if approximately 16 simultaneous tracking events are obtained on at least the first three passes. If we project an improvement in our knowledge and in our laser systems over the next few years, then in conjunction with Table 8 we can estimate the future quality of the results of the experiment. 
Table 9 shows the improvements that are projected by the authors for the major error sources. The means by which these improvements will come about will be primarily through the increased analysis of high quality laser range measurements on the existing and future planned geodetic type satellites. For example, the order of magnitude improvement in GM (Table 9) is expected to be obtained when future high altitude satellites, such as TIMATION 3 and LAGEOS (both carrying laser retro-reflectors), are launched in the next few years. Simulations at GSFC of the determination of GM from TIMATION (Carpenter) have indicated that a factor ten improvement is a very realizable objective. Similarly, in the case of the gravity field, an improvement over present day fields can be expected as more laser data is incorporated into the solutions, which are presently largely based on optical and radio tracking data of lower quality. Also, with the introduction of new techniques, such as satellite-to-satellite tracking and altimetry, our knowledge of the gravity field will improve even further.

In the present simulations, the uncertainty in the location of the San Diego station has been assumed to be 5 meters with respect to the earth's center of mass in each coordinate. This uncertainty is typical of present day optical tracking station cameras and reflects the general quality of the tracking system ( 2 arc seconds at $1000 \mathrm{~km}$ is about 10 meters). However, with the introduction of laser and other systems of about $10 \mathrm{~cm}$ accuracy, we anticipate that station locations will improve correspondingly to at least, say, 25 centimeters. Beyond this level careful consideration will have to be given to the inclusion of small scale 
tectonic and tidal motions of the kind being simulated here. Finally, laser system biases are expected to decrease to the few centimeter level from the simulated figure of $10 \mathrm{~cm}$ as a result of the introduction of short pulse laser systems (currently available) and improved calibration procedures presently being developed (Plotkin et al.).

Based on the above projections of our knowledge and capabilities, Table 10 has been prepared to show the precision of the baseline measurement that can be expected from an experiment started in 1972 and continuing through 1978. As has already been mentioned, the determination of the relative motions of the two sites will be derived by fitting a weighted least squares straight line through the results for the baseline (and other coordinates). Table 10 shows the projected standard deviation of the gradient of that line to be about $\pm 1 \mathrm{~cm} /$ year by 1976 and $\pm 0.4 \mathrm{~cm} /$ year by 1980 . There is, of course, a difference between the baseline direction and the boundary between the North American and Pacific plates. The baseline is inclined to the fault at an angle of about 25 degrees so that the standard deviation of the plate motion is about $10 \%$ Iarger than that of the change in baseline.

There are several small aspects of the experiment that have not been addressed specifically in these simulations. One of these concerns the solid-earth tides and polar motion, the former being equivalent to a variation in the height and the latter to a variation in latitude. Although these effects have not been modeled in the simulation, their effect can be assessed by inspection of the San Diego station 
position errors. Polar motion and earth tides will be modeled in the computer programs used in the analysis so it is with errors in these models that we are really concerned. The average error in the polar motion model is most unlikely to be more than $50 \mathrm{~cm}$ in any observation period ( 2 months). This figure is $10 \%$ of the assumed error of 5 meters in the latitude of San Diego, and from Table 4 (3-pass solution) we see that the effect on the baseline in any one year would be 6 or $7 \mathrm{~mm}$. If we assume that this varied from year to year, positive and negative, with a maximum of $50 \mathrm{~cm}$ error in pole position, then the rms standard deviation of the error in baseline would be about $4 \mathrm{~mm}$, showing that a knowledge of polar motion at the $50 \mathrm{~cm}$ level is adequate for the present. It should be remembered that this figure is the average error for a particular observation period and that larger day-to-day errors can be tolerated provided they are offset by errors of opposite sign.

A similar argument can be made about the earth tides. The full variation of the earth tides at a mid-latitude station is about $40 \mathrm{~cm}$ with a period of about 12 hours. Because the observation period is six hours, the effective amplitude will be reduced by about $30 \%$ to around $30 \mathrm{~cm}$ full variation. This error in height is about $6 \%$ of the Dan Diego error that has been simulated, and from Table 4 we see that the neglect of the earth tides on the baseline would contribute an error of 6 or 7 centimeters each year. Further, this figure assumes that the error would be a constant $30 \mathrm{~cm}$, whereas in reality, the periodic nature of the tides 
would cause the average tidal effect to be a factor 2 or 3 smaller. Thus, the effect of the earth tides on the station height does not appear to be a major problem for the experiment. Additionally, a model of the earth tides will be used in the analysis which should be accurate to at least $80 \%$, thereby limiting errors to less than a centimeter.

A further source of error that needs to be discussed is refraction. Tropospheric refraction of the ruby laser pulse at $6943 \AA$ is about 2.3 meters at zenith, and this can be computed to an accuracy of better than $1 \mathrm{~cm}$ from a knowledge of pressure, temperature, and humidity at the site (Hopfield). As the zenith angle increases, the refraction increases (approximately) according to the cosecant of the zenith angle so that at seventy degrees (20 degrees elevation) the error in the refraction is about $3 \mathrm{~cm}$. The effective minimum elevation for the experiment will be 20 degrees elevation, although 10 degrees (about $5 \mathrm{~cm}$ refraction error) was the limit used in this simulation. Thus, refraction is likely to be limited to a few centimeters in range and is generally smaller than the anticipated range biases of the systems and, therefore, of minor importance at the present time. However, as the systems improve to the $2 \mathrm{~cm}$ level toward the end of the decade, a corresponding improvement will be needed in the computation of refraction.

One final comment should be made. Any simulation of this magnitude has many associated subtleties that are not evident upon embarkment. Before arriving at the method of solution described here, numerous exploratory simulations were 
conducted. The approach presented here is quite successful, but may not necessarily be the best approach and further techniques will be investigated.

\section{CONCLUSIONS}

The results of this simulation have shown that laser ranging to satellites from two stations can be utilized for determining the relative motions along fault lines or tectonic boundaries to an accuracy level of better than $1 \mathrm{~cm} / \mathrm{year}$ averaged over several years. In particular, for the San Andreas Fault Experiment, it has been shown that there is good reason to believe that just 16 days of simultaneous tracking per year from two stations nearly $1000 \mathrm{~km}$ apart will be sufficient to detect motion to an accuracy of about $0.4 \mathrm{~cm} /$ year over six years.

Current knowledge of the motions of satellites limits the precision (each year) of the recovered chord length between the two laser sites to about $10 \mathrm{~cm}$, but it is estimated that gravity model and system improvements will lower this uncertainty to $3 \mathrm{~cm}$ by 1976 and to about $1.5 \mathrm{~cm}$ by 1980 . Six years of data anal lyzed in 1980 will yield a determination of the relative motion of the two plates on either side of the San Andreas fault to $\pm 0.4 \mathrm{~cm}$ per year.

\section{ACKNOWLEDGMENT}

The authors would like to acknowledge the valuable assistance of James $G$. Marsh of GSFC in the preparation of this simulation and in the subsequent discussions of the results. 


\section{REFERENCES}

Carpenter, L. (Edit.), "Preliminary Study of the Application of the TIMATION III Satellite to Earth Physics," Goddard Space Flight Center, X-553-72-50, March 1972.

Dunn, P. T., R. Kolenkiewicz and D. E. Smith, "An Experiment to Determine the Relative Positions of Two Collocated Laser Tracking Stations, "Goddard Space Flight Center, X-553-72-497, November 1972.

Escobal, P. R., K. M. Ong, O. H. von Roos, M. S. Shumate, R. M. Jaffee, H. F. Fliegel and P. M. Muller, "3-D Multilateration: A Precision Geodetic Measurement System," JPL Technical Memorandum 33-605, March 15, 1973.

Esposito, P. B. and S. K. Wong, "Geocentric Gravitational Constant Determined from Mariner 9 Radio Tracking Data, "presented at the International Symposium on Earth Gravity Models and Related Problems," St. Louis, August $16-18,1972$.

Guier, W. H. and R. R. Newton, "The Earth's Gravitational Field Deduced from the Doppler Tracking of Five Satellites," J. Geophys. Res., 70(18), 4613$4626,1965$.

Hopfield, H. S., "Tropospheric Range Error at the Zenith, "presented at 14th Plenary Meeting of COSPAR, Seattle, June 1971. 
Lundquist, C. A. and G. Veis, (Eds.) "Geodetic Parameters for a 1966

Smithsonian Institution Standard Earth," Vol. 1, Smithsonian Astrophysical Observatory Special Report 200, 1966.

Martin, C. F., "Error Analysis of Statistical Techniques Used in Orbit Estimation" Wolf Research and Development Corporation, Riverdale, Md., June 1969.

Martin, C. F. and N. A. Roy, "An Error Model for the SAO 1969 Standard Earth," The Use of Artificial Satellites for Geodesy, American Geophysical Union, Geophysical Monograph Series Vol. 15, 161-167, 1972.

Plotkin, H. H., T. S. Johnson and P. O. Minott, "Progress in Laser Ranging to Satellites: Achievements and PIans," First Int. Symp. on Use of Artificial Satellites for Geodesy and Geodynamics, Athens, May 1973.

Vonbun, F. O., "Analysis of the Range and Range Rate Tracking System," IRE Transactions On Space Electronics and Telemetry, Vol. SET-8, Number 2, June, 1962. 
Table 1

Periods for Which Simulated Data Were Prepared

\begin{tabular}{cccccccc}
\hline Year & Month & Days & Arcs & Month & Days & Arcs & $\begin{array}{c}\text { Total } \\
\text { Arcs }\end{array}$ \\
\hline 1970 & Aug & $19-26$ & 8 & Sep & $17-24$ & 8 & 16 \\
1971 & Aug & $12-19$ & 8 & Sep & $3-10$ & 8 & 16 \\
1972 & Aug & $13-20$ & 8 & Sep & $5-12$ & 8 & 16 \\
1973 & Aug & $9-16$ & 8 & Sep & $9-16$ & 8 & 16 \\
1974 & Aug & $14-21$ & 8 & Sep & $15-22$ & 8 & 16 \\
1975 & Aug & $9-16$ & 8 & Sep & $8-15$ & 8 & 16 \\
1976 & Aug & $13-20$ & 8 & Sep & $13-20$ & 8 & 16 \\
1977 & Aug & $8-15$ & 8 & Sep & $7-14$ & 8 & 16 \\
\hline
\end{tabular}


Table 2

Error Sources

\begin{tabular}{ll}
\hline \multicolumn{1}{c}{ Error Source } & \multicolumn{1}{c}{ Magnitude (1972) } \\
\hline Gravitational Constant, GM & $1 \times 10^{-6}$ \\
Gravity & $1 / 4$ APL 3.5, SAOM-1 Differences through \\
& Degree and Order 8 \\
Quincy Laser System Bias & 10 Centimeters \\
San Diego Laser System Bias & 10 Centimeters \\
Solar Radiation Pressure & $10 \%$ of Nominal Force \\
Atmospheric Drag & $10 \%$ of Nominal Force \\
Resonant Coefficients & $1 / 4$ Nominal Values for 19th Degree, \\
& 13 th Order \\
Laser Data Noise & 5 Meters \\
San Diego Latitude & 5 Meters \\
San Diego Height & 5 Meters \\
& 20 Centimeters \\
\hline
\end{tabular}


Table 3

Expected Errors in QUINCY Location for 2-pass Solution (Centimeters)

\begin{tabular}{|c|c|c|c|c|c|c|c|c|c|c|c|}
\hline \multirow{2}{*}{ Year } & \multirow{2}{*}{ GM } & \multirow{2}{*}{$\begin{array}{l}\text { Gravity } \\
\text { Model }\end{array}$} & \multirow{2}{*}{$\begin{array}{c}\text { Quincy } \\
\text { Bias }\end{array}$} & \multirow{2}{*}{$\begin{array}{l}\text { San Diego } \\
\text { Bias }\end{array}$} & \multirow{2}{*}{$\begin{array}{c}\text { Solar } \\
\text { Radiation }\end{array}$} & \multirow{2}{*}{$\begin{array}{c}\text { Atmosphtric } \\
\text { Drag }\end{array}$} & \multirow{2}{*}{$\begin{array}{c}C \\
19,13\end{array}$} & \multirow{2}{*}{$\begin{array}{c}S \\
19,13\end{array}$} & \multicolumn{3}{|c|}{ San Dicgo } \\
\hline & & & & & & & & & Longitude & Latitude & Height \\
\hline \multicolumn{12}{|c|}{ LONGITUDE } \\
\hline 1970 & 72 & 10 & 4 & 3 & 0 & 0 & 0 & -1 & $4 \$ 4$ & -33 & $-2 l$ \\
\hline 1971 & 81 & -29 & 4 & 3 & 0 & 0 & 0 & 0 & 454 & -35 & -26 \\
\hline 1972 & 86 & .34 & 4 & 3 & 0 & 0 & 1 & -1 & 454 & -34 & -31 \\
\hline 1973 & 76 & -4 & 4 & 2 & 0 & 0 & 0 & $n$ & 454 & -33 & -24 \\
\hline 1974 & 73 & -1 & 4 & 2 & 0 & 0 & 0 & -1 & 454 & .34 & -21 \\
\hline 1975 & 76 & -16 & 4 & 2 & 0 & 0 & 0 & 0 & 454 & -35 & -22 \\
\hline 1976 & 76 & -8 & 4 & 2 & 0 & 0 & 0 & 0 & 454 & -33 & -24 \\
\hline 1977 & 77 & -18 & 4 & 2 & 0 & 0 & 0 & 0 & 454 & .35 & -24 \\
\hline Average & 77 & -13 & 4 & 2.4 & 0 & 0 & .1 & -.4 & 454 & .34 & .24 \\
\hline RMS & 4.2 & 14 & 0 & .5 & 0 & 0 & .3 & .5 & 0 & .9 & 3.1 \\
\hline
\end{tabular}

L A T I T U D E

$\begin{array}{crrrrrrrrrrr}1970 & 33 B & -14 & -2 & 24 & 0 & 0 & 1 & 0 & 0 & 501 & -400 \\ 1971 & 321 & -45 & -4 & 25 & -1 & 0 & 0 & 0 & 0 & 510 & -383 \\ 1972 & 372 & -56 & -4 & 27 & 0 & 0 & 0 & 0 & 0 & 512 & -432 \\ 1973 & 338 & -33 & -2 & 24 & 0 & 0 & 0 & 1 & 0 & 505 & -399 \\ 1974 & 325 & -23 & -3 & 24 & 0 & 0 & 0 & 0 & 0 & 504 & -385 \\ 1975 & 322 & -39 & -3 & 24 & 0 & 0 & 0 & 0 & 0 & 508 & -382 \\ 1976 & 331 & -33 & -3 & 23 & 0 & 0 & 0 & 0 & 0 & 504 & -390 \\ 1977 & 325 & -40 & -3 & 24 & 0 & 0 & 0 & 1 & 0 & 508 & -386 \\ \text { Averikgc } & 334 & -35 & -3.0 & 24 & .1 & 0 & .1 & .3 & 0 & 507 & -395 \\ \text { RMS } & 16 & 12 & .7 & 1.1 & .3 & 0 & .3 & .4 & 0 & 3.4 & 16\end{array}$

H E I $\quad$; H T

\begin{tabular}{|c|c|c|c|c|c|c|c|c|c|c|c|}
\hline 19711 & 446 & -16 & 20 & to & 0 & 1) & 0 & 0 & 0 & 28 & 32 \\
\hline 1971 & 537 & .7 & 18 & 19 & -1 & 0 & -1 & 0 & n & 37 & -68 \\
\hline 1972 & 5.38 & -55 & 18 & 17 & 0 & 0 & 0 & j & 0 & 37 & .59 \\
\hline 1973 & 484 & .14 & 20 & 13 & 11 & 0 & 0 & 0 & 0 & 32 & -7 \\
\hline 1974 & 456 & -26 & 20 & 11 & "I & 0 & (I & 0 & 0 & 30 & 23 \\
\hline 1975 & 494 & . 10 & 19 & 15 & () & II & 0 & 0) & 0 & 33 & .20 \\
\hline 1976 & 455 & -26 & 19 & 11 & 0 & 0 & 1) & 0 & 0 & 30 & 27 \\
\hline 1977 & Sil & .17 & 19 & 15 & 0 & 0 & 0 & 0 & 0 & 35 & -33 \\
\hline Averalge & 4911 & -21 & 19 & 14 & -.1 & 0 & -.1 & 0 & 0 & 33 & .13 \\
\hline R.MS & 34 & 14 & .8 & 3.0 & .3 & 0 & .3 & 0 & (1 & 3.2 & 36 \\
\hline
\end{tabular}

B A $\quad$ A I: L L I $\quad$ N $\quad$ !:

\begin{tabular}{|c|c|c|c|c|c|c|c|c|c|c|c|}
\hline 1970 & 309 & -18 & $\cdot 2$ & 21 & 0 & 0 & 1 & 0 & 0 & 8 & .317 \\
\hline 1971 & 246 & .29 & .4 & 23 & .1 & 0 & 0 & 0 & 0 & 18 & -306 \\
\hline 1972 & 340 & -41 & -4 & 24 & 0 & () & 0 & 0 & 0 & 19 & -348 \\
\hline 1973 & 310 & -29 & -2 & 22 & 4 & 0 & () & 1 & 0 & 12 & -317 \\
\hline 1974 & 297 & -22 & -3 & 22 & 0 & 0 & 0 & 0 & 0 & 12 & -304 \\
\hline 1975 & 296 & .30 & $\cdot 3$ & 22 & 0 & 0 & 0 & 0 & 0 & 16 & -304 \\
\hline 1976 & 301 & .29 & $\cdot 3$ & 21 & 0 & 0 & 0 & (1) & ) & 11 & -307 \\
\hline 1977 & 299 & -30 & $\cdot 3$ & 22 & 0 & (1) & 0 & 1 & 0) & 16 & -307 \\
\hline Aterase & 306 & -24 & -3.11 & 22 & -.1 & n & .1 & .3 & 0 & 14 & -314 \\
\hline RWS & 14 & 6.3 & .7 & .9 & .3 & 1) & .3 & .4 & 0 & 3.6 & 14 \\
\hline
\end{tabular}


Table 4

Expected Errors in QUINCY Location for 3-pass Solution (Centimeters)

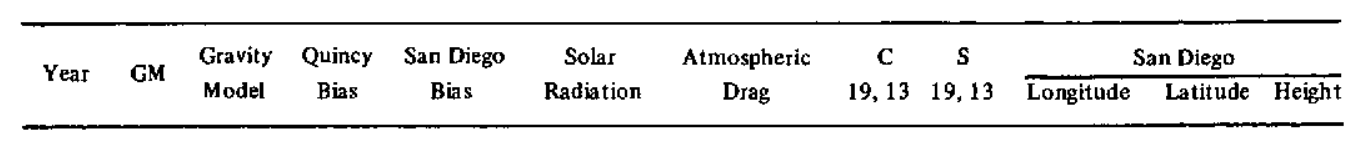

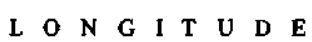

$\begin{array}{crrrrrrrrrrr}1970 & 54 & 6 & 3 & 2 & 0 & 0 & 0 & 0 & 454 & -27 & -11 \\ 1971 & 46 & 10 & 3 & 1 & 0 & 0 & 0 & 1 & 454 & -30 & 1 \\ 1972 & 53 & 7 & 3 & 2 & 0 & 0 & 1 & 0 & 454 & -29 & -7 \\ 1973 & 54 & 0 & 3 & 2 & 0 & 0 & 0 & 0 & 454 & -27 & -10 \\ 1974 & 53 & 4 & 3 & 2 & 0 & 0 & 0 & -1 & 454 & -28 & -9 \\ 1975 & 50 & 2 & 3 & 2 & 0 & 0 & 0 & 0 & 454 & -29 & -4 \\ 1976 & 56 & 3 & 3 & 2 & 0 & 0 & 0 & 0 & 454 & -27 & -12 \\ 1977 & 52 & -2 & 3 & 2 & 0 & 0 & 0 & 0 & 454 & -28 & -6 \\ \text { Average } & 52 & 3.8 & 3 & 1.9 & 0 & 0 & .1 & 0 & 454 & -28 & -7.3 \\ \text { RMS } & 2.9 & 3.6 & 0 & .3 & 0 & 0 & .3 & .5 & 0 & 1.1 & 3.5\end{array}$

$\begin{array}{lllllllll}\text { L } & \text { A } & \mathbf{T} & \mathbf{I} & \mathrm{T} & \mathrm{U} & \mathrm{D} & \mathbf{E}\end{array}$

$\begin{array}{rrrrrrrrrrrr}1970 & 112 & -88 & -2 & 8 & -1 & -1 & 1 & 0 & 0 & 480 & -179 \\ 1971 & 101 & -96 & -3 & 9 & -2 & -1 & 0 & 0 & 0 & 494 & -161 \\ 1972 & 118 & -77 & -3 & 9 & 0 & -1 & 1 & 0 & 0 & 492 & -180 \\ 1973 & 111 & -92 & -2 & 8 & 0 & -1 & 0 & 0 & 0 & 485 & -175 \\ 1974 & 112 & -81 & -3 & 8 & 0 & -1 & 1 & 0 & 0 & 486 & -176 \\ 1975 & 106 & -89 & -3 & 9 & 1 & -1 & 0 & 0 & 0 & 490 & -168 \\ 1976 & 113 & -100 & -3 & 8 & 1 & -1 & 1 & 0 & 0 & 485 & -176 \\ 1977 & 107 & -90 & -3 & 8 & 0 & -1 & 0 & 0 & 0 & 490 & -169 \\ \text { Average } & 110 & -89 & -2.8 & 8.4 & -.1 & -1 & .5 & 0 & 0 & 488 & -173 \\ \text { RMS } & 4.8 & 7.0 & -4 & .5 & .9 & 0 & .5 & 0 & 0 & 4.3 & 6.0\end{array}$

H E I G H T

$\begin{array}{cccccccccccc}1970 & 314 & 283 & 21 & 1 & 0 & 1 & 0 & 0 & 0 & 13 & 177 \\ 1971 & 316 & 333 & 21 & 1 & 0 & 1 & 0 & 1 & 0 & 11 & 166 \\ 1972 & 332 & 274 & 20 & 1 & 0 & 1 & 1 & 0 & 0 & 15 & 156 \\ 1973 & 325 & 246 & 20 & 1 & 0 & 1 & 0 & 0 & 0 & 15 & 165 \\ 1974 & 316 & 258 & 21 & 1 & 0 & 1 & 0 & 0 & 0 & 14 & 174 \\ 1975 & 320 & 285 & 21 & 1 & 0 & 1 & 0 & 0 & 0 & 13 & 167 \\ 1976 & 322 & 236 & 20 & 1 & 0 & 1 & 0 & 0 & 0 & 15 & 170 \\ 1977 & 326 & 244 & 20 & 1 & 1 & 1 & 0 & 0 & 0 & 15 & 162 \\ \text { Average } & 321 & 270 & 21 & 1 & .1 & 1 & .1 & .1 & 0 & 14 & 168 \\ \text { RMS } & 5.7 & 29 & .5 & 0 & .3 & 0 & .3 & .3 & 0 & 1.4 & 6.2\end{array}$

B A S E L I N

\begin{tabular}{rrrrrrrrrrrr}
1970 & 102 & -62 & -2 & 7 & -1 & -1 & 1 & 0 & 0 & -14 & -110 \\
1971 & 95 & -68 & -2 & 8 & -2 & -1 & 0 & 0 & 0 & 0 & -99 \\
1972 & 109 & -53 & -3 & 7 & 0 & -1 & 1 & 0 & 0 & -2 & -113 \\
1973 & 102 & -66 & -2 & 7 & 0 & -1 & 0 & 0 & 0 & -9 & -107 \\
1974 & 102 & -57 & -2 & 7 & 0 & -1 & 1 & 0 & 0 & -8 & -108 \\
1975 & 98 & -61 & -2 & 7 & 1 & -1 & 0 & 0 & 0 & -4 & -103 \\
1976 & 102 & -75 & -3 & 7 & 1 & -1 & 1 & 0 & 0 & -9 & -107 \\
1977 & 99 & -64 & -3 & 7 & 0 & -1 & 0 & 0 & 0 & -5 & -104 \\
Average & 101 & -63 & -2.4 & 7.1 & -.1 & -1 & .5 & 0 & 0 & -6.4 & -106 \\
RMS & 3.8 & 6.3 & .5 & .3 & .9 & 0 & .5 & 0 & 0 & 4.2 & 4.1 \\
\hline
\end{tabular}


Table 5

Expected Errors in QUINCY Location for 4-pass Solution (Centimeters)

\begin{tabular}{|c|c|c|c|c|c|c|c|c|c|c|c|}
\hline \multirow{3}{*}{ Year } & \multirow{3}{*}{ GM. } & \multirow{3}{*}{$\begin{array}{l}\text { Gravity } \\
\text { Model }\end{array}$} & \multirow{3}{*}{$\begin{array}{c}\text { Quincy } \\
\text { Bias }\end{array}$} & \multirow{3}{*}{$\begin{array}{c}\text { San Diego } \\
\text { Bias }\end{array}$} & \multirow{2}{*}{$\begin{array}{c}\text { Solar } \\
\text { Radiation }\end{array}$} & \multirow{2}{*}{$\begin{array}{c}\text { Atmospheric } \\
\text { Drag }\end{array}$} & \multirow{3}{*}{$\begin{array}{c}C \\
19,13\end{array}$} & \multirow{3}{*}{$\begin{array}{c}S \\
19,13\end{array}$} & \multicolumn{3}{|c|}{ San Diego } \\
\hline & & & & & & & & & Longitude & Latitude & Height \\
\hline & & & & & L $\quad$ O $\quad \mathrm{N} \quad \mathrm{C}$ & I $\mathbf{T}$ U $\mathbf{D}$ & & & & & \\
\hline 1970 & 2 & -82 & 1 & 0 & 0 & -1 & 0 & 0 & 454 & -23 & 37 \\
\hline 1971 & 17 & .103 & 2 & 0 & -1 & -1 & 0 & 0 & 454 & -23 & 27 \\
\hline 1972 & 23 & -103 & 2 & 1 & 0 & -1 & 0 & 0 & 454 & .23 & 21 \\
\hline 1973 & 10 & -87 & 2 & 0 & $\cdot 1$ & -1 & 0 & 0 & 454 & -23 & 30 \\
\hline 1974 & 6 & -86 & 2 & 0 & -1 & -1 & 0 & 0 & 454 & -23 & 35 \\
\hline 1975 & 14 & -95 & 2 & 0 & 0 & -1 & 0 & 0 & 454 & -23 & 29 \\
\hline 1976 & 8 & -81 & 2 & 0 & 0 & -1 & 0 & 0 & $4 \$ 4$ & -23 & 32 \\
\hline 1977 & 15 & -95 & 2 & 0 & 0 & -1 & 0 & 0 & 454 & -23 & 28 \\
\hline Average & 12 & -92 & 1.9 & .1 & -.4 & -1 & 0 & 0 & 454 & -23 & 30 \\
\hline RMS & 6.3 & 8.2 & .3 & .3 & .5 & 0 & 0 & 0 & 0 & 0 & 4.6 \\
\hline
\end{tabular}

L A $\quad$ T I T U D E

$\begin{array}{crrrrrrrrrrr}1970 & -25 & -245 & -4 & 0 & -1 & -2 & 0 & 0 & 0 & 465 & -38 \\ 1971 & 24 & -305 & -4 & 4 & -2 & -2 & 0 & -1 & 0 & 480 & -80 \\ 1972 & 19 & -311 & -3 & 3 & 1 & -2 & 0 & 1 & 0 & 475 & -75 \\ 1973 & -9 & -258 & 4 & 1 & 0 & -2 & -1 & 0 & 0 & 469 & -52 \\ 1974 & -15 & -257 & -4 & 1 & 0 & -2 & 0 & 1 & 0 & 469 & -45 \\ 1975 & 8 & -285 & -4 & 3 & 1 & -2 & 0 & 0 & 0 & 475 & -67 \\ 1976 & -17 & -255 & -4 & 1 & 0 & -2 & 0 & 1 & 0 & 467 & -42 \\ 1977 & 7 & -275 & -4 & 2 & 1 & -2 & -1 & 0 & 0 & 474 & -65 \\ \text { Average } & -1 & -274 & -3.9 & 1.9 & 0 & -2 & -.3 & .3 & 0 & 472 & -58 \\ \text { RMS } & 17 & 23 & .3 & 1.3 & 1.0 & 0 & .4 & .7 & 0 & 4.7 & 15\end{array}$

H E I G H T

$\begin{array}{rrrrrrrrrrrr}1970 & 182 & 104 & 19 & -6 & 0 & 0 & 0 & 1 & 0 & 8 & 339 \\ 1971 & 224 & 157 & 20 & -4 & 1 & 0 & 0 & 1 & 0 & 8 & 287 \\ 1972 & 242 & 76 & 19 & -3 & 1 & 0 & 0 & 1 & 0 & 10 & 275 \\ 1973 & 212 & 87 & 19 & -4 & -1 & 0 & 0 & 1 & 0 & 9 & 306 \\ 1974 & 196 & 96 & 19 & -5 & -1 & 0 & 0 & 1 & 0 & 8 & 324 \\ 1975 & 216 & 122 & 19 & -4 & 1 & 0 & 0 & 1 & 0 & 9 & 298 \\ 1976 & 203 & 94 & 19 & -5 & -1 & 0 & 0 & 1 & 0 & 8 & 317 \\ 1977 & 227 & 94 & 19 & -4 & 1 & 0 & 0 & 1 & 0 & 9 & 288 \\ \text { Average } & 213 & 104 & 19 & -4.4 & -1 & 0 & 0 & 1 & 0 & 8.6 & 304 \\ \text { RMS } & 18 & 24 & .3 & .9 & .9 & 0 & 0 & 0 & 0 & .7 & 20\end{array}$

B A S E L I N E

\begin{tabular}{rrrrrrrrrrrr}
1970 & -11 & -181 & -3 & 0 & -1 & -1 & 0 & 0 & 0 & -30 & 10 \\
1971 & 31 & -223 & -3 & 3 & -1 & -1 & 0 & -1 & 0 & -16 & -28 \\
1972 & 25 & -234 & -2 & 2 & 1 & -1 & 0 & 1 & 0 & -21 & -22 \\
1973 & 3 & -192 & -3 & 1 & 0 & -1 & -1 & 0 & 0 & -26 & -2 \\
1974 & -2 & -191 & -3 & 1 & 0 & -1 & 0 & 1 & 0 & -26 & 3 \\
1975 & 17 & -211 & -3 & 2 & 1 & -1 & 0 & 0 & 0 & -21 & -16 \\
1976 & -4 & -191 & -3 & 1 & 0 & -1 & 0 & 1 & 0 & -28 & 7 \\
1977 & 16 & -204 & -3 & 2 & 1 & -1 & -1 & 0 & 0 & -22 & -14 \\
Avesage & 9.4 & -203 & -2.9 & 1.5 & .1 & -1 & -.3 & .3 & 0 & -24 & -7.8 \\
RMS & 14 & 17 & .3 & .9 & .8 & 0 & .4 & .7 & 0 & 4.3 & 13 \\
\hline
\end{tabular}


Table 6

Expected Errors in QUINCY Location for 5-pass Solution (Centimeters)

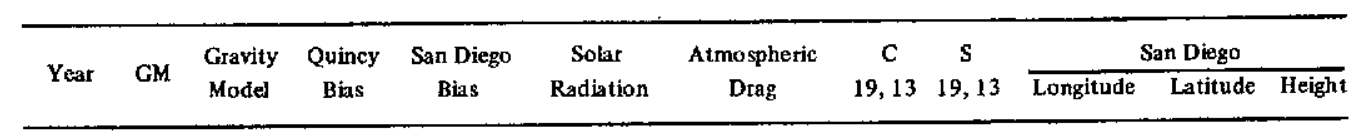

L $O$ O N

$\begin{array}{cccccccccccc}1970 & -17 & -59 & 0 & -1 & 0 & -1 & 0 & 0 & 454 & -22 & 43 \\ 1971 & -22 & -72 & 1 & -1 & -1 & -1 & 0 & 0 & 454 & -25 & 51 \\ 1972 & -19 & -61 & 1 & -1 & 0 & -1 & 0 & 0 & 454 & -24 & 48 \\ 1973 & -18 & -58 & 0 & -1 & 0 & -1 & 0 & 0 & 454 & -22 & 45 \\ 1974 & -19 & -62 & 0 & -1 & 0 & -1 & 0 & 0 & 454 & -22 & 45 \\ 1975 & -19 & -67 & 0 & -1 & 0 & -1 & 0 & 0 & 454 & -24 & 48 \\ 1976 & -17 & -55 & 0 & -1 & 0 & -1 & 0 & 0 & 454 & -22 & 43 \\ 1977 & -21 & -64 & 1 & -1 & 0 & -1 & 0 & 0 & 454 & -24 & 49 \\ \text { Average } & -19 & -62 & .4 & -1 & -.1 & -1 & 0 & 0 & 454 & -23 & 47 \\ \text { RMS } & 1.7 & 5.0 & .5 & 0 & .3 & 0 & 0 & 0 & 0 & .1 .2 & 2.7\end{array}$

L $\begin{array}{lllllll}\text { A } & \text { T } & \text { I } & \text { T } & \text { U } & \text { D } & \mathbf{E}\end{array}$

$\begin{array}{crrrrrrrrrrr}1970 & -42 & -117 & -6 & 0 & 0 & -1 & 0 & 0 & 0 & 476 & -42 \\ 1971 & -38 & -158 & -6 & 0 & 0 & -1 & 0 & -1 & 0 & 475 & -42 \\ 1972 & -53 & -137 & -5 & 0 & 1 & -1 & 0 & 0 & 0 & 469 & -26 \\ 1973 & -48 & -114 & -6 & 0 & 0 & -1 & 0 & 0 & 0 & 473 & -33 \\ 1974 & -43 & -125 & -6 & 0 & 1 & -1 & 0 & 0 & 0 & 474 & -39 \\ 1975 & -43 & -142 & -6 & 0 & 1 & -1 & 0 & 0 & 0 & 474 & -38 \\ 1976 & -48 & -117 & -6 & 0 & 0 & -1 & 0 & 0 & 0 & 473 & -33 \\ 1937 & -47 & -127 & -5 & 0 & 0 & -1 & 0 & 0 & 0 & 473 & -33 \\ \text { Average } & -45 & -130 & -5.8 & 0 & .4 & -1 & 0 & -.1 & 0 & 473 & -36 \\ \text { RMS } & 4.4 & 14 & .4 & 0 & .5 & 0 & 0 & .3 & 0 & 1.9 & 5.1\end{array}$

H $\quad$ E I $\quad$ G

$\begin{array}{crrrrrrrrrrr}1970 & 81 & 95 & 17 & -11 & 0 & 0 & 0 & 0 & 0 & -18 & 425 \\ 1971 & 72 & 136 & 17 & -12 & 2 & 0 & 0 & 0 & 0 & -18 & 430 \\ 1972 & 88 & 102 & 17 & -11 & 3 & 0 & 0 & 0 & 0 & -18 & 421 \\ 1973 & 89 & 85 & 17 & -11 & 0 & 0 & 0 & 0 & 0 & -18 & 420 \\ 1974 & 82 & 89 & 17 & -11 & 0 & 0 & 0 & 0 & 0 & -18 & 425 \\ 1975 & 83 & 105 & 17 & -11 & 1 & 0 & 0 & 0 & 0 & -17 & 424 \\ 1976 & 90 & 93 & 17 & -11 & -1 & 0 & 0 & 0 & 0 & -18 & 419 \\ 1977 & 87 & 88 & 17 & -11 & 0 & 0 & 0 & 0 & 0 & -18 & 421 \\ \text { Average } & 84 & 99 & 17 & -11 & .7 & 0 & 0 & 0 & 0 & -18 & 423 \\ \text { RMS } & 5.5 & 15 & 0 & .3 & 1.2 & 0 & 0 & 0 & 0 & .3 & 3.4\end{array}$

B A S E L 1 N E

\begin{tabular}{crrrrrrrrrrr}
1970 & -25 & -75 & -4 & 0 & 0 & 0 & 0 & 0 & 0 & -31 & 10 \\
1971 & -20 & -104 & -5 & 0 & 1 & 0 & 0 & -1 & 0 & -22 & 7 \\
1972 & -34 & -92 & -4 & 0 & 1 & 0 & 0 & 0 & 0 & -28 & 22 \\
1973 & -30 & -73 & -4 & 0 & 0 & 0 & 0 & 0 & 0 & -25 & 17 \\
1974 & -25 & -82 & -4 & 0 & 1 & 0 & 0 & 0 & 0 & -24 & 12 \\
1975 & -25 & -94 & -4 & 0 & 1 & 0 & 0 & 0 & 0 & -23 & 11 \\
1976 & -30 & -77 & -4 & 0 & 0 & 0 & 0 & 0 & 0 & -25 & 18 \\
1977 & -28 & -83 & -4 & 0 & 0 & 0 & 0 & 0 & 0 & -24 & 15 \\
Average & -27 & -85 & -4.1 & 0 & .5 & 0 & 0 & -1 & 0 & -25 & 14 \\
RMS & 4.0 & 10 & .3 & 0 & .5 & 0 & 0 & .3 & 0 & 2.7 & 4.6 \\
\hline
\end{tabular}


Table 7

Expected Errors in QUINCY Location for Middle-3-pass Solution (Centimeters)

\begin{tabular}{|c|c|c|c|c|c|c|c|c|c|c|c|}
\hline \multirow{3}{*}{ Year } & \multirow{2}{*}{ GM } & \multirow{2}{*}{$\begin{array}{l}\text { Gravity } \\
\text { Model }\end{array}$} & \multirow{2}{*}{$\begin{array}{l}\text { Quincy } \\
\text { Bias }\end{array}$} & \multirow{2}{*}{$\begin{array}{c}\text { San Diego } \\
\text { Bias }\end{array}$} & \multirow{2}{*}{$\begin{array}{c}\text { Solar } \\
\text { Radiation }\end{array}$} & \multirow{2}{*}{$\begin{array}{l}\text { Almospheric } \\
\text { Drag }\end{array}$} & \multirow{2}{*}{$\begin{array}{c}\text { G } \\
19,13\end{array}$} & \multirow{2}{*}{$\begin{array}{c}S \\
19,13\end{array}$} & \multicolumn{3}{|c|}{ San Diego } \\
\hline & & & & & & & & & Longitude & Laditude & Height \\
\hline & & & & & $\begin{array}{llll} & O & N & G\end{array}$ & 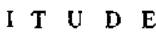 & & & & & \\
\hline 1970 & -10 & 60 & 1 & -1 & 0 & 0 & 0 & 0 & 454 & .20 & 36 \\
\hline 1971 & 23 & 24 & 1 & 1 & -1 & 0 & 0 & 1 & 454 & -21 & 7 \\
\hline 1972 & 24 & 35 & 1 & 1 & 0 & -1 & 0 & 0 & 454 & -20 & 6 \\
\hline 1973 & 3 & 41 & 1 & 0 & 0 & -1 & 0 & 0 & 454 & -20 & 24 \\
\hline 1974 & -1 & 57 & 1 & 0 & -1 & -1 & 0 & 0 & 454 & -20 & 29 \\
\hline 1975 & 16 & $3 s$ & 1 & 1 & 0 & -1 & 0 & 0 & 454 & -20 & 13 \\
\hline 1976 & -2 & 55 & 1 & 0 & 0 & -1 & 0 & 0 & 454 & -21 & 29 \\
\hline 1977 & 15 & 30 & 1 & 1 & 0 & 0 & o & 0 & 454 & -20 & 13 \\
\hline Average & 8.5 & 42 & 1 & .4 & -.3 & -6 & 0 & -1 & 454 & -20 & 20 \\
\hline RMS & 12 & . 13 & 0 & .7 & .4 & .5 & 0 & .3 & 0 & .4 & 11 \\
\hline
\end{tabular}

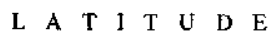

$\begin{array}{rrrrrrrrrrrr}1970 & -54 & -59 & -3 & -2 & 0 & 0 & 0 & -1 & 0 & 455 & -9 \\ 1971 & -70 & -122 & -4 & -3 & 1 & 0 & 0 & -1 & 0 & 445 & 8 \\ 1972 & -94 & -60 & -4 & -4 & 1 & -1 & 0 & -1 & 0 & 442 & 38 \\ 1973 & -55 & -75 & -3 & -2 & 1 & 0 & 0 & -1 & 0 & 454 & -7 \\ 1974 & -61 & -52 & -3 & -3 & 1 & 0 & 0 & -1 & 0 & 451 & 0 \\ 1975 & -59 & -98 & -4 & -2 & 1 & 0 & 0 & -1 & 0 & 449 & -3 \\ 1976 & -57 & -66 & -3 & -2 & 1 & 0 & 0 & -1 & 0 & 452 & -4 \\ 1977 & -59 & -86 & -3 & -2 & 0 & 0 & 0 & -1 & 0 & 449 & -2 \\ \text { Avcrage } & -64 & -77 & -3.4 & -2.5 & .8 & -.1 & 0 & -1 & 0 & 450 & 2.6 \\ \text { RMS } & 12 & 22 & .5 & .7 & .4 & .3 & 0 & 0 & 0 & 4.1 & 14\end{array}$

$\begin{array}{lllllllllllllll}H & E & \text { I } & G & H & T\end{array}$

$\begin{array}{cccccccccccc}1970 & 3017 & 291 & 21 & 0 & 0 & 0 & 0 & 1 & 0 & 22 & 202 \\ 1971 & 307 & 219 & 21 & 1 & 0 & 0 & 0 & 1 & 0 & 25 & 201 \\ 1972 & 330 & 196 & 21 & 1 & 1 & 0 & 0 & 0 & 0 & 26 & 180 \\ 1973 & 321 & 224 & 21 & 1 & 0 & 0 & 0 & 0 & 0 & 23 & 188 \\ 1974 & 310 & 274 & 21 & 1 & -1 & 0 & 0 & 0 & 0 & 23 & 198 \\ 1975 & 313 & 234 & 21 & 1 & 0 & 0 & 0 & 0 & 0 & 24 & 195 \\ 1976 & 318 & 254 & 21 & 1 & -1 & 0 & 0 & 0 & 0 & 23 & 191 \\ 1977 & 320 & 201 & 21 & 1 & 0 & 0 & 0 & 0 & 0 & 24 & 189 \\ \text { Average } & 316 & 237 & 21 & .9 & -.1 & 0 & 0 & .3 & 0 & 24 & 193 \\ \text { RMS } & 7.5 & 32 & 0 & .3 & .6 & 0 & 0 & .4 & 0 & 1.2 & 7.0\end{array}$

B A S S E

\begin{tabular}{|c|c|c|c|c|c|c|c|c|c|c|c|}
\hline 1970 & .23 & -58 & -2 & -1 & 0 & 0 & 0 & -1 & 0 & -39 & 27 \\
\hline 1971 & -51 & .105 & -3 & -3 & $\mathfrak{l}$ & 0 & 0 & -1 & 0 & -48 & 54 \\
\hline 1972 & -72 & -55 & -3 & -4 & 1 & 0 & 0 & -1 & 0 & -51 & 80 \\
\hline 1973 & -28 & -69 & -2 & -2 & 1 & 0 & n) & -1 & 0 & -40 & 33 \\
\hline 1974 & -33 & $-5 \mathbf{j}$ & -2 & -3 & 1 & 0 & 0 & -1 & 0 & -43 & 38 \\
\hline 1975 & -38 & -87 & -3 & -2 & 1 & 0 & 0 & -1 & 0 & -44 & 41 \\
\hline 1976 & -28 & -65 & -2 & -2 & $\mathfrak{I}$ & 0 & 0 & -1 & 0 & 41 & 34 \\
\hline 1977 & -37 & -76 & -2 & -2 & 0 & 0 & 0) & ו- & 0 & -44 & 42 \\
\hline Average & -39 & $-7 t$ & -2.4 & -2.4 & .8 & 0 & 0 & -1 & 0 & 44 & 44 \\
\hline RMS & 15 & 17 & .5 & .9 & .4 & 0 & 0 & 0 & 0 & 3.8 & 16 \\
\hline
\end{tabular}


Table 8

Components of the Baseline Precision

(All units are centimeters, figures based on 1972-73 capability and knowledge)

\begin{tabular}{|c|c|c|c|c|c|c|c|c|c|c|c|c|}
\hline \multirow{2}{*}{ Solution } & \multirow{2}{*}{ GM } & \multirow{2}{*}{$\begin{array}{l}\text { Grav. } \\
\text { Model }\end{array}$} & \multirow{2}{*}{$\begin{array}{c}\text { Quincy } \\
\text { Bias }\end{array}$} & \multirow{2}{*}{$\begin{array}{c}\text { San } \\
\text { Diego } \\
\text { Bias }\end{array}$} & \multirow{2}{*}{$\begin{array}{l}\text { Sol. } \\
\text { Rad. }\end{array}$} & \multirow{2}{*}{$\begin{array}{l}\text { Atm. } \\
\text { Drag }\end{array}$} & \multirow{2}{*}{$C(19,13)$} & \multirow[b]{2}{*}{$\mathrm{S}(19,13)$} & \multicolumn{3}{|c|}{ San Diego } & \multirow{2}{*}{ RSS } \\
\hline & & & & & & & & & Long. & Lat. & Ht. & \\
\hline 2-pass & 14 & 6 & 0.7 & 0.9 & 0.3 & $-0-$ & 0.3 & 0.4 & $-0-$ & 4 & 14 & 21 \\
\hline 3 -pass & 4 & 6 & 0.5 & 0.3 & 0.9 & $-0-$ & 0.5 & $-0-$ & $-0-$ & 4 & 4 & 9 \\
\hline 4-pass & 14 & 17 & 0.3 & 0.9 & 0.8 & $-0-$ & 0.4 & 0.7 & $-0-$ & 4 & 13 & 26 \\
\hline 5 -pass & 4 & 10 & 0.3 & $-0-$ & 0.5 & $-0-$ & $-0-$ & 0.3 & $-0-$ & 3 & 5 & 12 \\
\hline $\begin{array}{l}\text { Middle } \\
\text { 3-pass }\end{array}$ & 15 & 17 & 0.5 & 0.9 & 0.4 & $-0-$ & $-0-$ & $-0-$ & $-0-$ & 4 & 16 & 28 \\
\hline
\end{tabular}


Table 9

Expected Improvements in the Major Error Sources

\begin{tabular}{ccc}
\hline Error Source & Projected \\
& Factor Improvement over & $1972 / 73$ Capability \\
GM & 1976 & 1980 \\
Gravity Field & 10 & 20 \\
San Diego Latitude & 3 & 7 \\
San Diego Height & 5 & 20 \\
Laser System Biases & 5 & 20 \\
\hline
\end{tabular}


Table 10

Projected Ability to Recover SAFE Baseline (Centimeters)

\begin{tabular}{|c|c|c|c|}
\hline \multirow{2}{*}{$\begin{array}{c}\text { Data } \\
\text { Collected }\end{array}$} & \multicolumn{3}{|c|}{ Year Data Analyzed } \\
\hline & 1972 & 1976 & 1980 \\
\hline 1972 & 9 & 3 & 2.0 \\
\hline 1973 & & 3 & 2.0 \\
\hline 1974 & & 3 & 2.0 \\
\hline 1975 & & 3 & 2.0 \\
\hline 1976 & & 3 & 1.5 \\
\hline 1977 & & & 1.5 \\
\hline 1978 & & & 1.5 \\
\hline Accuracy & Motion & \pm 1.0 & \pm 0.4 \\
\hline Accuracy & tion (cr & \pm 1.1 & \pm 0.4 \\
\hline
\end{tabular}

Note: Improvements are due to increased accuracy of force models, station position determinations and improved laser systems. 


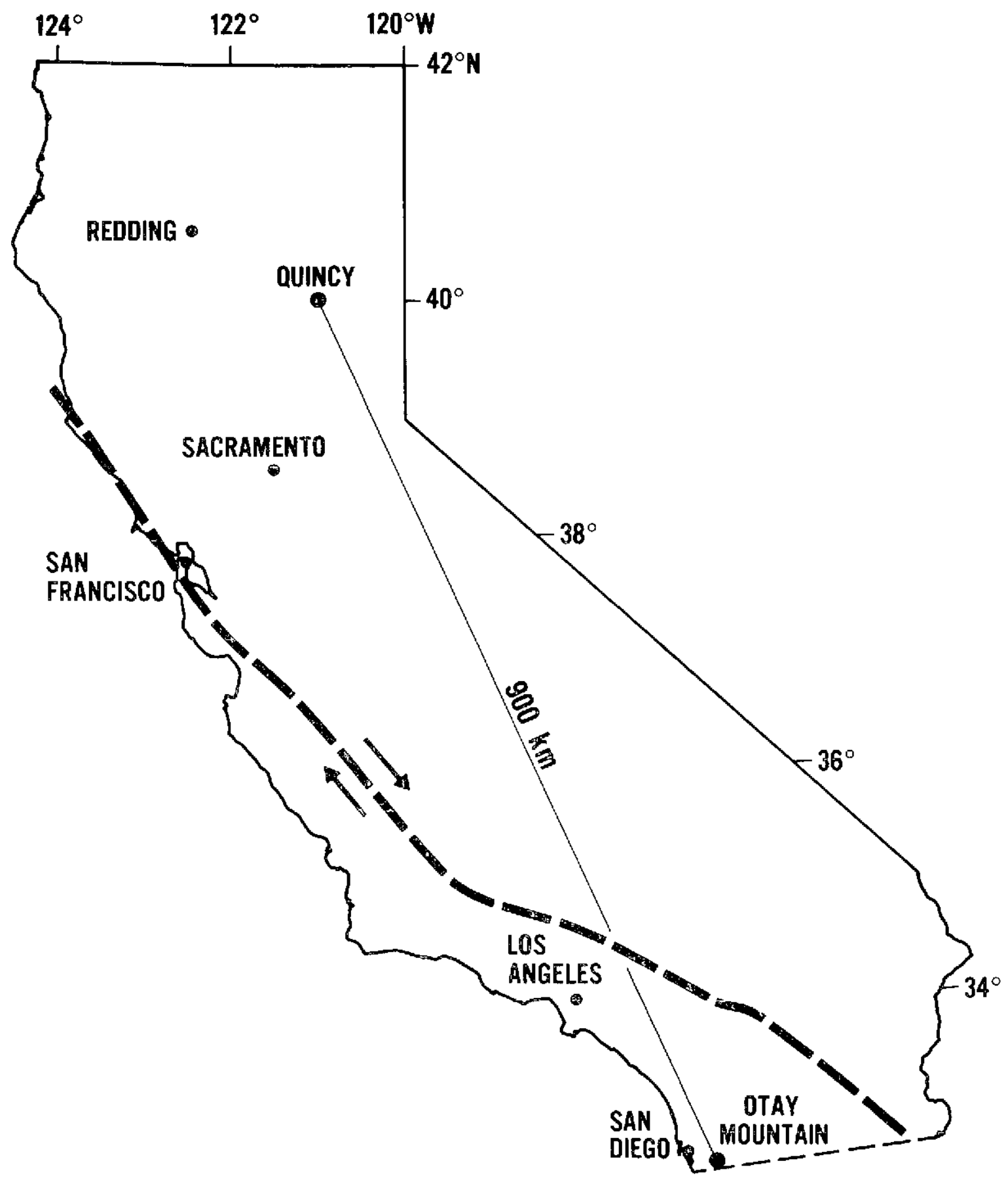

Figure 1. The San Andreas Fault Experiment, 1972 


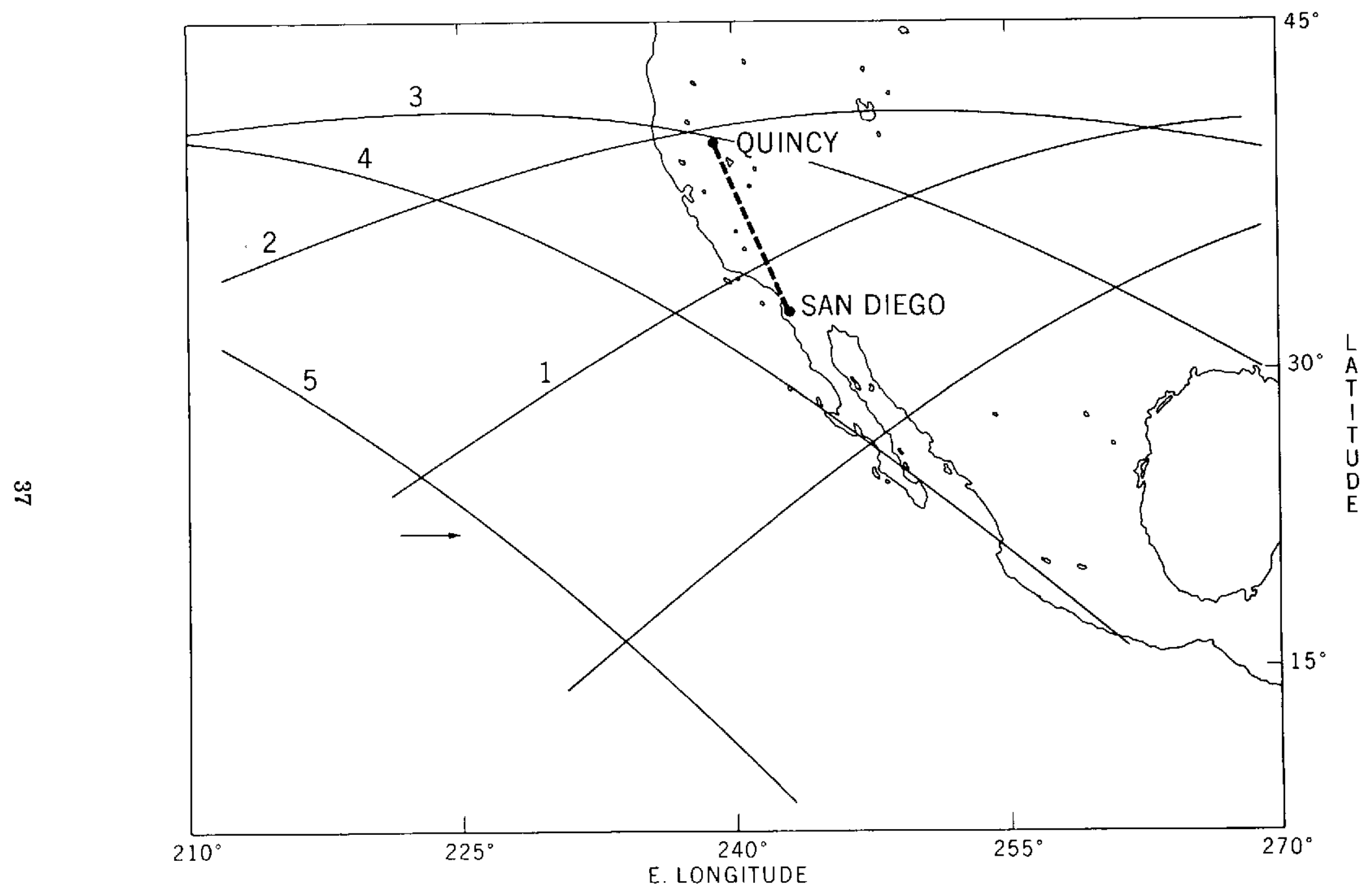

Figure 2. Groundtracks of 5 Consecutive Passes of the BE-C Satellite During the San Andreas Fault Experiment (SAFE) 


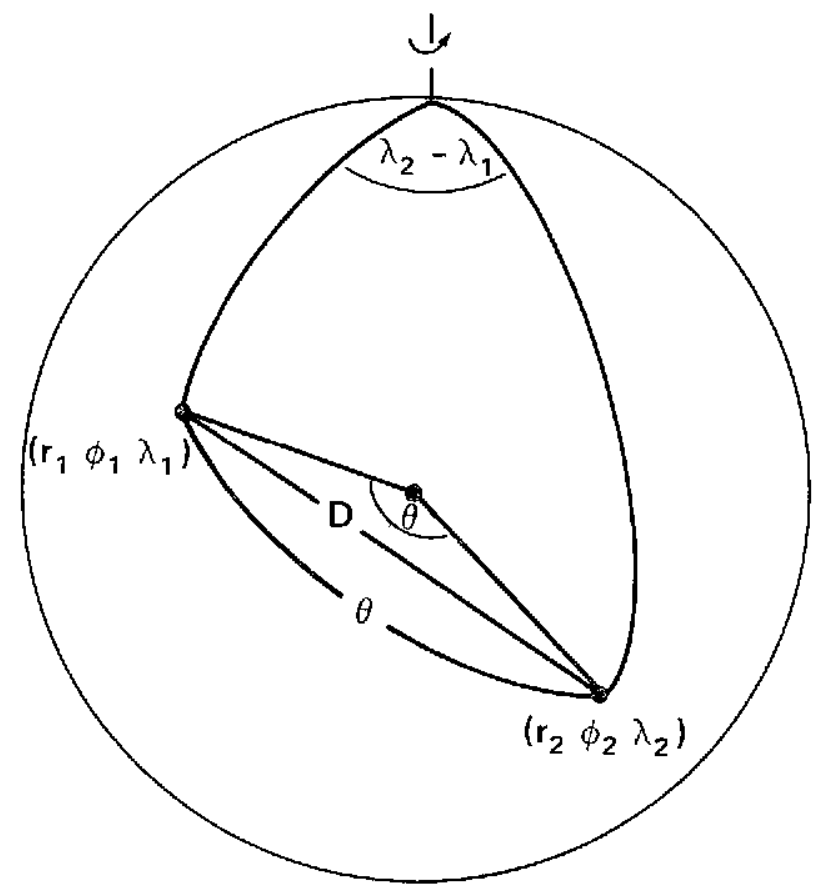

Figure 3. Geocentric Coordinates of Tracking Stations 